\title{
Analysis of the Wounding Potential of SELECTED WEAPONS OF CATEGORY D
}

\section{Michal GRAClA*, MichaElA MikUlicova \& ZDENEK MALANIK}

Abstract: Interest in firearms has been increasing recently, and it is, therefore, necessary to deal with the possible firearms injuries that these weapons can cause. Gunshot wounds depend on the wounding potential which firearms can cause. The wounding potential is commonly tested on the replacement material. In this paper, an experimental measurement is used. The first measurement is based on the post-firing products left on the paper, and the second one is based on the depth of the shot of two types of pellets fired from the airgun. To prove or disprove the ability of the wounding potential of the investigated weapons, it is then necessary to determine the possible degree of injury caused to the soft tissue of the human body. The results are essential for further investigation and future research of gunshot wounds caused by tested weapons.

Key words: weapon of category D, ammunition, wounding potential, experiment
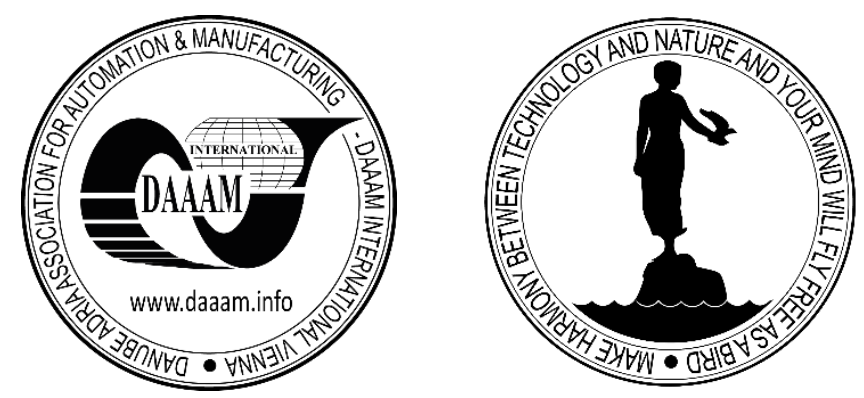

Authors' data: Michal Gracla*, Michaela Mikulicova \& Zdenek Malanik, Tomas Bata University in Zlin, Nad Stranemi 4511, 76005 Zlín, CZ, gracla@utb.cz

This Publication has to be referred as: Gracla, M[ichal]; Mikulicova, M[ichaela] \& Malanik, Z[denek] (2020). Analysis of the Wounding Potential of Selected Weapons of Category D, Chapter 21 in DAAAM International Scientific Book 2020, pp.245252, B. Katalinic (Ed.), Published by DAAAM International, ISBN 978-3-902734-273, ISSN 1726-9687, Vienna, Austria

DOI: $10.2507 /$ daaam.scibook.2020.21 


\section{Introduction}

Weapons have been accompanying humankind since time immemorial. Over time, weapons have improved to their present form. Legislation must respond to the development of weapons and should therefore also be adapted. In recent years, there has been a growing interest in defence using a firearm or other self-defence device. This interest was caused by the increasing danger of terrorist attacks and also by the migration crisis.

Shooting weapons can be divided into three basic types: mechanical, firearm and gas. Besides, the Czech Act No. 119/2002 Coll., On Firearms and Ammunition divides weapons into four categories, labelled A, B, C and D. Weapons of category A are prohibited for civilian use, weapons of category $\mathrm{B}$ require an authorisation, weapons of category $\mathrm{C}$ require notification, and weapons of category $\mathrm{D}$ are freely available from the age of 18 .

Many papers are devoted to lethal weapons of categories A, B and C; however, only a few papers deal with the effects of weapons of category D. It is the interest in these weapons that grows most because of their easy availability and low cost. Research on these non-lethal weapons is thus an essential source of information for various disciplines, such as medicine, forensic analysis, ballistics and more.

At first glance, it may not be apparent whether the weapon is lethal or nonlethal, and it is, therefore, essential to examine the appearance of the weapon [1]. To determine the level of threat and danger of individual firearms, experimental measurements [2], [3], [4] are taken. For this reason, it is necessary to have information on individual impact velocities [5], [6] of individual missiles of firearms. In some cases, firearms are not used for an attack but can be used for suicide [7], which is an entirely different method of use that is not primarily tested. These real cases can be used to design further experimental testing, but mainly to make a qualified determination of the wounding effect from experimental tests, from which only wounding potential can currently be determined.

In this paper, two types of firearms classified as weapons of category D are investigated. The first firearm is an expansion weapon, which is characterised by not firing any projectile. Although expansion weapons are considered harmless by the lay public, they can cause serious injuries. The question of whether expansion weapons are dangerous or not was researched in [8]. The wounding potential of expansion weapons was investigated in [9], ammunition into these weapons was examined in [10]. The second examined firearm is an air rifle, in which two types of pellets are used. The aim of this article is to analyse the wounding potential of these selected weapons of category D. 


\section{Investigated weapons}

According to Czech law, the weapons of category D include a large number of different shooting weapons ranging from firearms to gas and mechanical weapons. In this paper, expansion firearm and the gas gun were examined, namely the Umarex Walther P22 expansion gun and the TEX 086 air rifle. The experimental measurement methodology was described for each of these weapons.

Each of the investigated weapons uses different ammunition. The first firearm (expansion weapon) uses cartridges. Three types of cartridges were used for the experimental measurements: acoustic, acoustic flashlight and pepper. The second firearm (air rifle) uses pellets. Two types of pellets were chosen for experimental measurement: pellets PRO MATCH and pellets COBRA.

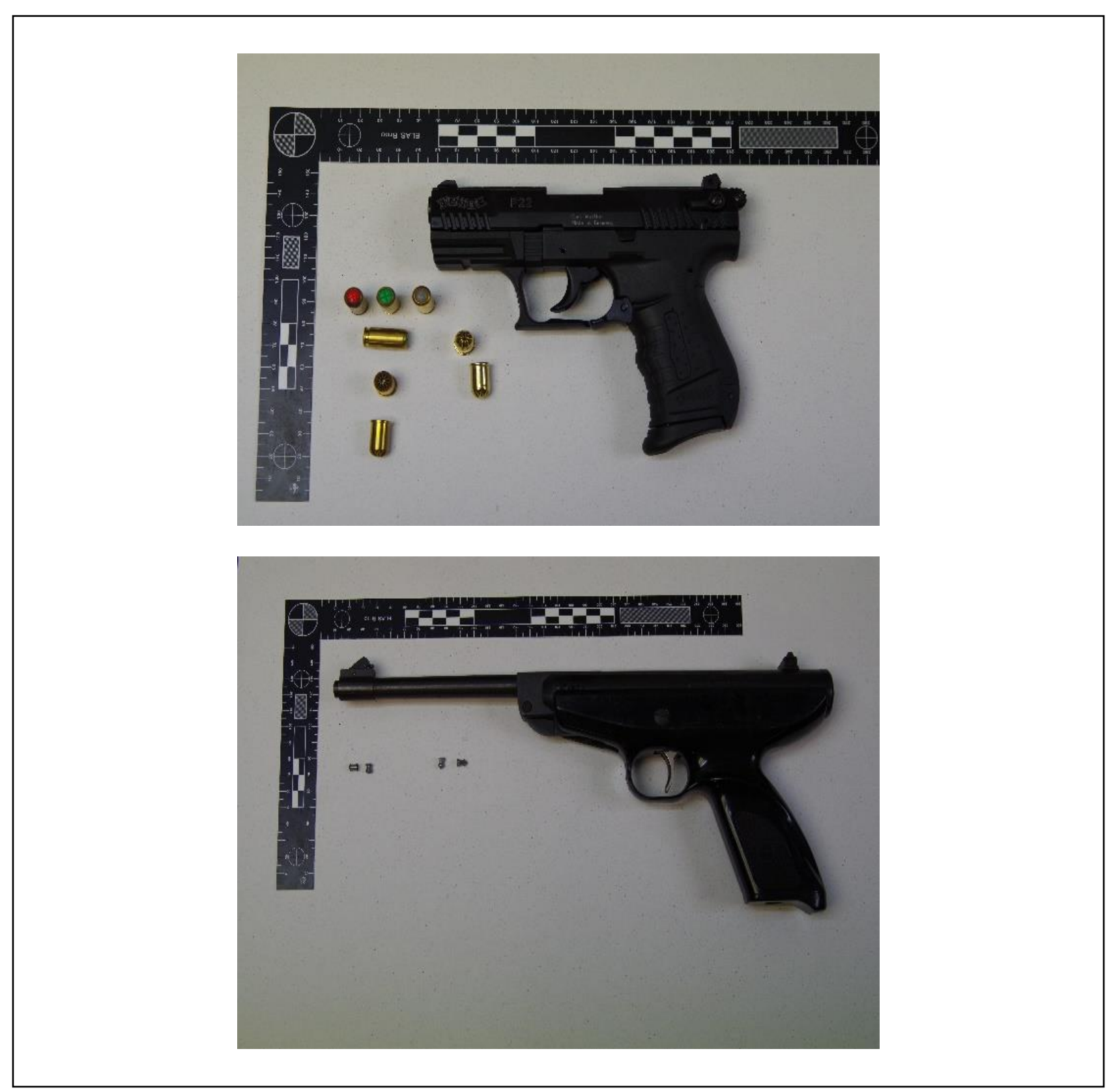

Fig. 1. The Umarex Walther P22 expansion gun (left) and the TEX 086 air rifle (right). 


\section{Methods}

Experimental measurements were performed partially at the shooting range Trigger Service, s.r.o. in Brno and partially in the laboratory at the Faculty of Applied Informatics, at Tomas Bata University in Zlin. In both experimental measurements, there was a constant temperature of $18{ }^{\circ} \mathrm{C}$.

The expansion weapon was used for the first experimental measurement. In this measurement, the amount of post-firing fumes at different distances from the muzzle of the expansion weapon to the test material was examined.

The size of the paper used was A3 paper with an area of $1247 \mathrm{~cm} 2$, which corresponds to the body of an adult male. The paper was coated with glue to better trap the grains of post-firing fumes. The tested distances were $0.25 \mathrm{~m}, 0.5 \mathrm{~m}, 1 \mathrm{~m}, 1.5 \mathrm{~m}$ and $2 \mathrm{~m}$ from the muzzle of the expansion weapon.
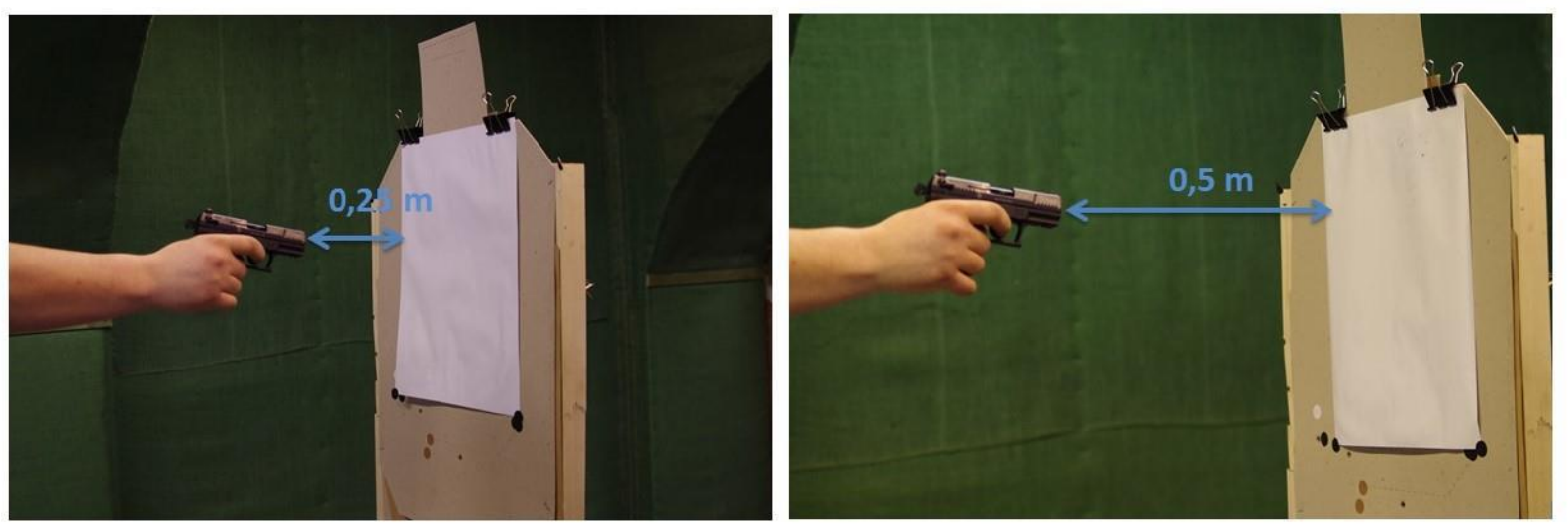

Fig. 2. Experimental setup for the first experiment

In the second experimental measurement, the wounding potential of the air rifle was determined by firing into a replacement material (a plasticine block with a density of $1.99 \pm 0.01 \mathrm{~g} / \mathrm{cm} 3)$.

Then, the depth of penetration of the pellet into this material was determined. The experimental workstation consisted of a firing stool, which was used to fasten the tested air rifle, and the underlying material, on which the replacement material was placed. During the experimental measurement, the replacement material was fired three times for each distance. Five different distances were selected: $0 \mathrm{~m}$ (contact), $0.25 \mathrm{~m}, 0.5 \mathrm{~m}$, $1 \mathrm{~m}$ and $2 \mathrm{~m}$. A calliper was used to measure the depths of penetration of the pellets into the replacement material. 


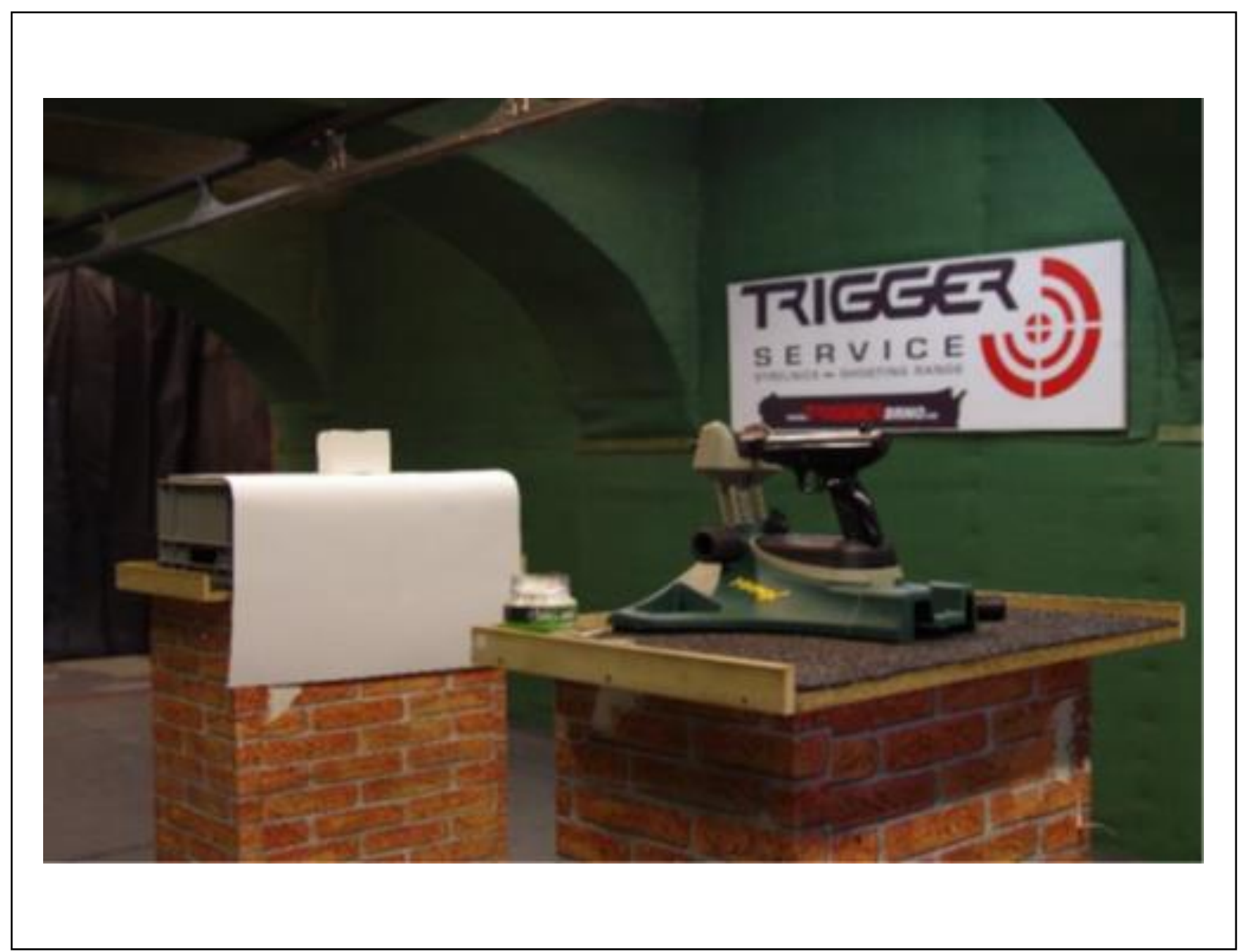

Fig. 3. Experimental setup for the second experiment

\section{Results}

The aim of the experiments was to analyse the amount of post-firing fumes at different distances from the muzzle of the expansion weapon to the test material and to determine the wounding potential of the air rifle. From the measurements described above, the following results were obtained. Fig. 1 shows the dependence of grains of post-firing fumes on the distance from the muzzle of the expansion weapon. As can be seen, the amount of post-firing fumes trapped on the test paper decreases with increasing distance from the target.

Moreover, the acoustic flashlight cartridge and the acoustic cartridge have approximately a half the amount of captured post-firing fumes at a distance of $1 \mathrm{~m}$ than a pepper cartridge. This is because the pepper cartridge contains technical pepper, which is mixed with the propellant charge, it does not burn when fired.

At a distance greater than $1 \mathrm{~m}$, the amount of grains of the post-firing fumes collected is almost identical, since it is so far from the muzzle that only a small amount of unburned propellant charge, post-firing fumes and technical pepper can travel the distance to the test paper. Furthermore, the diameter of the post-firing fumes is so large compared to the test paper that fumes could not be captured. 


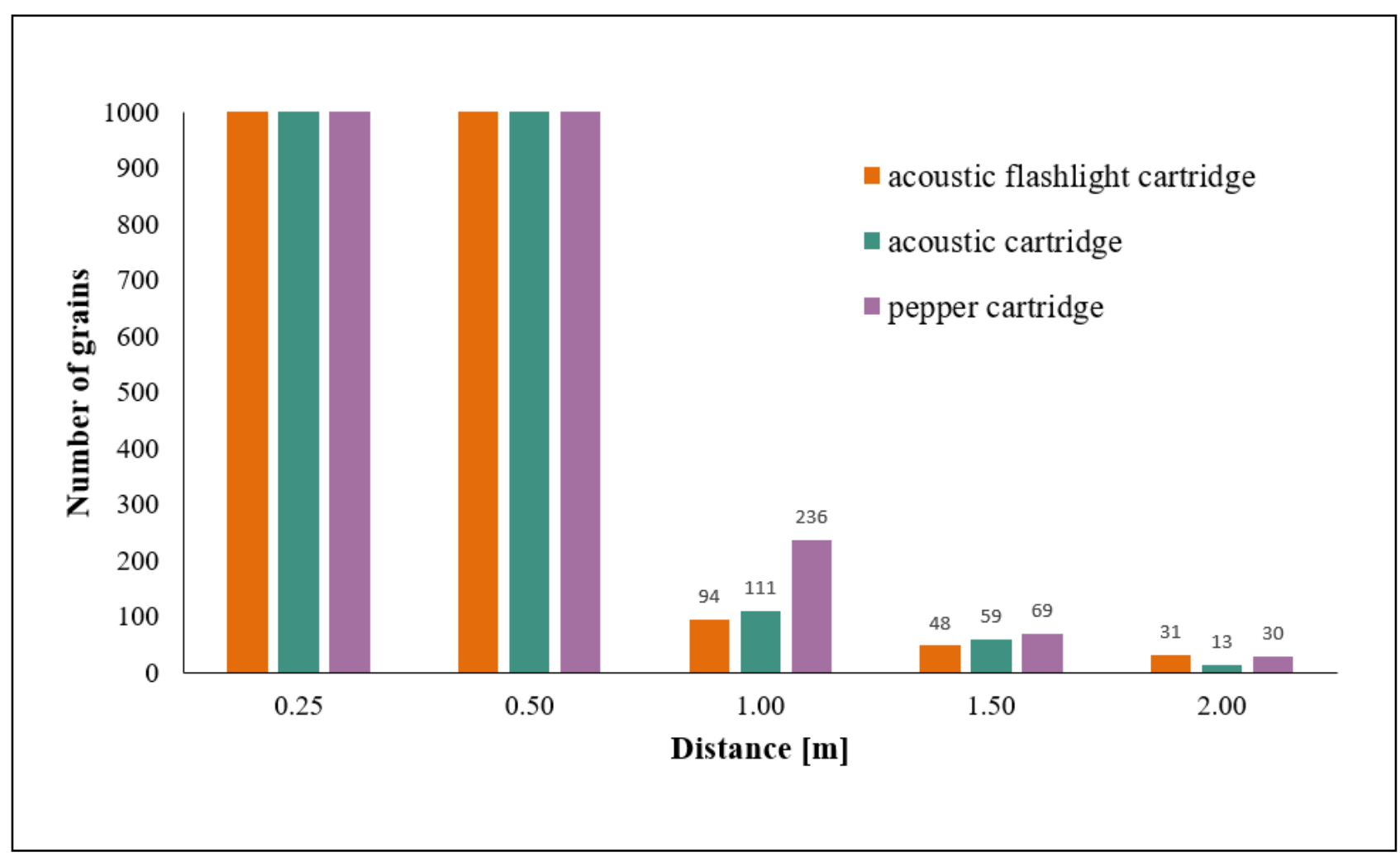

Fig. 4. The dependence of grains of post-firing fumes on the distance from the muzzle of the expansion weapon

Fig. 2 shows the dependence of penetration depth on distance. As can be seen, PRO MATCH pellets have a lower wounding potential than COBRA pellets, although both types of pellets were fired from the same firearm. The most significant difference in the wounding potential of COBRA pellet was at a distance of $0.5 \mathrm{~m}$ when it penetrated $1.7 \mathrm{~mm}$ deeper than the PRO MATCH pellet.

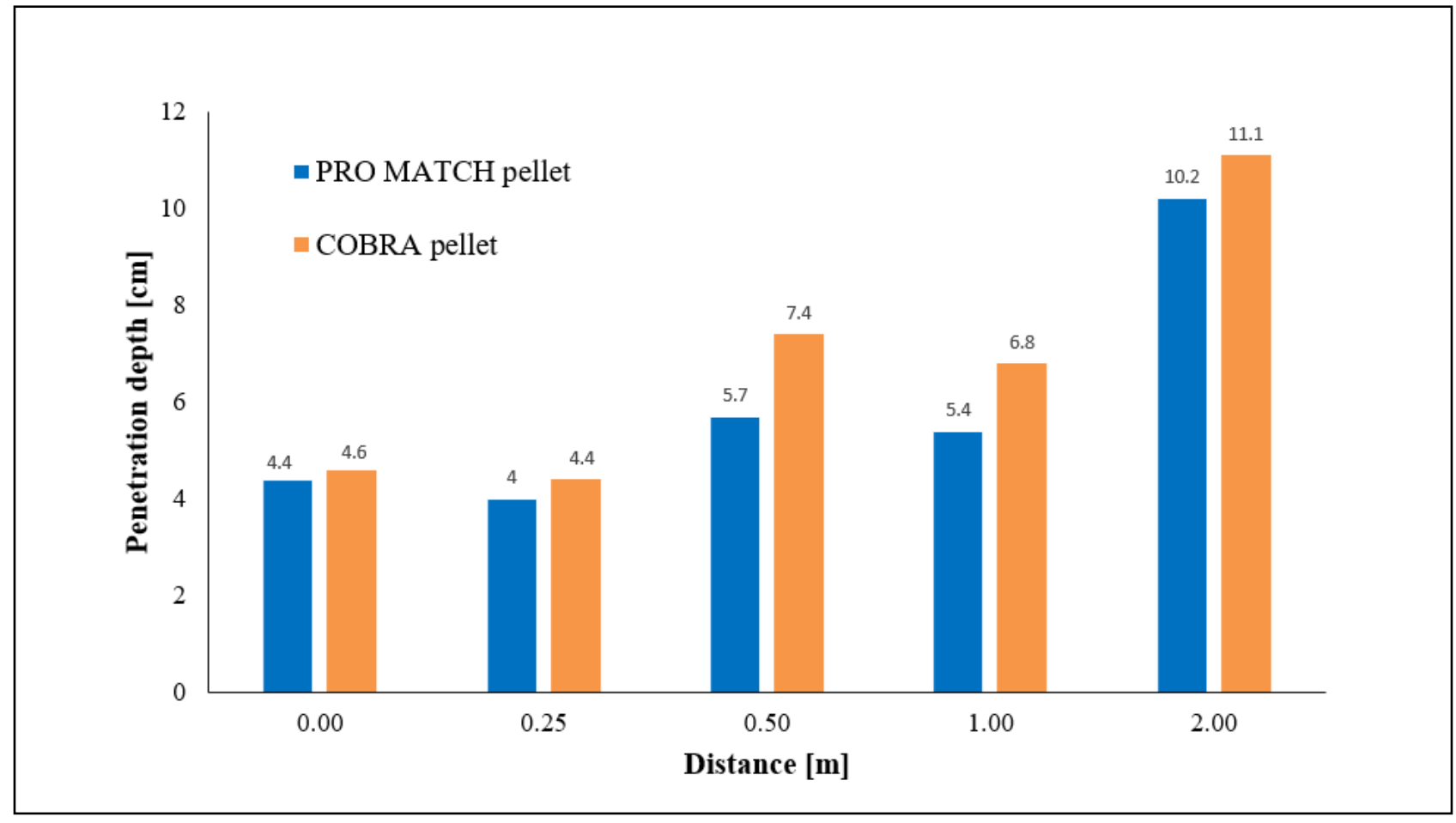

Fig. 5. The dependence of penetration depth on distance 


\section{Conclusion}

The aim of this paper was to analyse the wounding potential of selected weapons of category $\mathrm{D}$. The given results indicate that selected weapons of category $\mathrm{D}$, which were an expansion weapon and an air rifle, may not cause any injury, but may also cause mild to moderate gunshot injuries or even death. In many cases, gunshot wounds depend on the area hit by the missile. Moreover, in the case of an expansion weapon, the distance also depends. There was no damage at the tested distances on the test paper except for the captured grains of the post-firing fumes. However, if the respiratory tract is affected by post-firing fumes, they may cause respiratory problems.

In the case of the shooting of two different types of pellets from the air rifle, it is evident that the pellets have penetrated the replacement material with a minimum shot depth of $4 \mathrm{~mm}$ at a distance of $0.25 \mathrm{~m}$. At a distance of $2 \mathrm{~m}$, the first type of pellets reached a depth of over $10 \mathrm{~mm}$ and the second type even over $11 \mathrm{~mm}$. This shows that people should treat weapons of category D as they do with any other lethal weapon, mostly handle them properly and follow the recommendations of manufacturers and dealers of these weapons.

Nevertheless, further research is needed to confirm the results. In this paper, only two firearms classified in category D have been tested, and therefore, the conclusions should be evaluated with caution. Consequently, one of the challenges for future research is to conduct more experiments with multiple types of firearms classified in category $\mathrm{D}$, as well as the use of multiple types of ammunition for these firearms.

\section{Acknowledgements}

This work was supported by the Internal Grant Agency of Tomas Bata University under the project No. IGA/FAI/2019/003.

\section{References}

Gracla, M[ichal]; Mikulicova, M[ichaela] \& Malanik, Z[denek] (2018). Detecting Differences at a Selected Shooting Weapon and Its Freely Available Copies, Proceedings of the 29th DAAAM International Symposium, pp.1139-1143, B. Katalinic (Ed.), Published by DAAAM International, ISBN 978-3-90273420-4, ISSN 1726-9679, Vienna, Austria

DOI: 10.2507/29th.daaam.proceedings. 163

Ogunc, G.I., Ozer, M.T., Eryilmaz, M., Karakus, O. \& Uzar, A.I. (2014). The wounding potential and legal situations of air guns - experimental study. Australian Journal of Forensic Sciences, Vol. 46, No. 1, pp 39-52. ISSN 0045-0618. DOI: http://dx.doi.org./10.1080/00450618.2013.789078

Stefanopulos, P.K., Hadjigeorgiou, G.F., Filippakis, K. \& Gyftokostas, D. (2014). Gunshot wounds: A review of ballistics related to penetrating trauma. Journal of Acute Disease, pp 178-185. DOI: 10.1016/S2221-6189(14)60041-X 
Gracla, M.; Mikulicova, M. \& Malanik, Z.: Analysis of the Wounding Potential of ...

Koene, B., Id-Boufker, F. \& Papy, A. (2008). Kinetic Non-Lethal Weapons. Netherlands Annual Review of Military Studies, pp 9-24. In: Hupkens, T. \& Monsuur, H. [eds]: Sensors, Weapons, C4I and Operations Research.

Campbell, B. Ballistic Pendulum and Conservation of Momentum. Formal report for Lab \#8, Physics 4A

Hsiao, Y. \& Meng, H. (2018). Estimating the Impact Velocity of Airgun Pellet Via Terminal Ballistic Experiments. Forensic Science Journal, Vol. 17(1), pp 27-36. DOI: 10.6593/FSJ.2018.1701.04

Mogni, B. \& Maines, S. (2019). Homicide Using an Air Weapon. Clinical Practice and Cases in Emergency Medicine, in press. DOI: 10.5811/cpcem.2019.6.42982.

Gülşen, I., Ak, H., Sosuncu, E. \& Bulut, M. D. (2014). Are blank cartridge guns really harmless? Ulus Travma Acil Cerrahi Derg, Vol. 20, No. 3, pp. 214-216. DOI: 10.5505/tjtes.2014.90868

Ficek, M[artin]; Juricek, L[udvik] \& Mikulicova, M[ichaela] (2018). Expansion Weapons and their Wounding Potential, Proceedings of the 29th DAAAM International Symposium, pp.0786-0790, B. Katalinic (Ed.), Published by DAAAM International, ISBN 978-3-902734-20-4, ISSN 1726-9679, Vienna, Austria DOI: 10.2507/29th.daaam.proceedings.114

Salem, H., Katz, S.A., Feasel, M. \& Ballantyne, B. (2014). CS. Encyclopedia of Toxicology, Vol. 1, pp. 1076-1081. DOI: http://dx.doi.org/10.1016/B978-0-12-386454-3.00598-4 